\title{
Education Research: Electronic patient portal enrollment and no-show rates within a neurology resident clinic
}

Kavit Shah, MD, Abdullah Alshammaa, MD, Muhammad Affan, MD, Lonni Schultz, PhD, Tobias Walbert, MD, $\mathrm{PhD}$, and Iram Zaman, DO

Neurology ${ }^{\circledR}$ 2019;92:50-54. doi:10.1212/WNL.0000000000006685
Correspondence

Dr. Shah

shahkb2@upmc.edu

\section{Abstract \\ Objective}

To identify factors that affect appointment adherence and investigate the association of electronic patient portal $(\mathrm{ePP})$ enrollment and patient adherence rates to appointments in the Neurology Resident Clinic (NRC).

\section{Methods}

Patients scheduled for an appointment during the months of October 2015, February 2016, and June 2016 in the NRC were included. ePP enrollment, date of clinic appointment, method of referral to the clinic, and key demographic criteria were collected. $\chi^{2}$ tests were performed to assess the association of appointment status (i.e., no-show, showed, and canceled) with demographic, comorbidity, and visit information.

\section{Results}

Patients with ePP enrollment had significantly lower rates of no-show (19\% vs 27\%) and higher rates of showed (59\% vs $48 \%$ ) compared to patients without ePP enrollment. Younger patients (18-49) had the highest rates of no-show (28\%), while older patients $(65+)$ had the lowest rates of no-show (17\%). Caucasian patients had significantly lower rates of no-show compared to non-Caucasian patients ( $14 \%$ vs $24 \%$ ). Non-English-speaking patients had high rates of noshow (34\%). Patients with a physician referral had significantly lower rates of no-show ( $20 \%$ vs $28 \%)$ and higher rates of showed (61\% vs $44 \%)$ compared to patients with a self-referral.

\section{Conclusions}

Our study indicates that ePP enrollment, age, race, and physician referral might be associated with reduced no-show rates in the NRC.

\section{Introduction}

A nationwide increase in the adoption of electronic medical records (EMRs) by office-based physicians occurred from 2001 to 2015 (18.2\% to $86.9 \%$, respectively). ${ }^{1-3}$ A majority of EMRs use an electronic patient portal (ePP), which allows patients to securely communicate with health care providers. ${ }^{4-6}$ Thus far, implementing ePPs has yielded mixed results regarding clinic visit attendance; however, considerable variability exists in the methodology and scope of these studies. ${ }^{4-7}$

During academic year 2016-2017, 14,100 patients were seen in our neurology department's outpatient clinic. Currently, a 2-month waiting list exists for new patient visits, which is predicted to lengthen with increased demand. Anecdotally, there have been frequent no-shows to clinic, predominantly in the neurology resident clinic (NRC). This leads to unfilled patient slots and prevents those on an extended waitlist from being seen expeditiously. The effect of

From the Departments of Neurology (K.S., A.A., M.A., T.W., I.Z.), Public Health Sciences (L.S.), and Neurosurgery (T.W.), Henry Ford Hospital, Detroit, MI.

Go to Neurology.org/N for full disclosures. Funding information and disclosures deemed relevant by the authors, if any, are provided at the end of the article. 


\section{Glossary}

EMR = electronic medical record; $\mathbf{e P P}=$ electronic patient portal; IRB = institutional review board; NRC = neurology resident clinic.

ePP electronic reminders upon patient adherence rates to clinic appointments remains unclear. In this study, we investigate how ePP enrollment, key demographic factors, and referral methods are associated with patient adherence rates to NRC appointments.

\section{Methods}

Our health system's EMR is Epic (Epic Systems Corporation, Verona, WI), which has been used in our outpatient clinics since 2013. MyChart is its accompanying ePP, and similar to other ePPs, delivers automatic appointment reminders. We reviewed patients scheduled in the NRC, which consists of a patient population scheduled with 18 neurology residents, during the months of October 2015, February 2016, and June 2016. These months were chosen to capture different time points during the academic calendar. We conducted a retrospective chart review of the following data: date of scheduled clinic visit, appointment status, MyChart enrollment, sex, age, race, preferred language, and method of referral to the clinic. Patients were defined as (1) no-shows (did not appear for or canceled the appointment $<24$ business hours from the appointment time), (2) showed (attended the scheduled visit), and (3) canceled (canceled $\geq 24$ business hours prior to appointment).

\section{Standard protocol approvals, registration, and patient consent}

This retrospective study was approved by our institutional review board (IRB \#10780). Given the nature of the study, the informed consent requirement was waived by the IRB. No experiments on live vertebrates or higher invertebrates were performed. No photographs, videos, or other recognizable information regarding participating patients has been submitted for publication.

\section{Statistical analysis}

We performed $\chi^{2}$ tests to assess the association of appointment status (no-show, showed, and canceled) with MyChart enrollment, as well as predefined demographic, comorbidity, and visit information. We also used $\chi^{2}$ tests to assess the association of MyChart enrollment with the predefined demographic, comorbidity, and visit information. Multinomial logistic regression analysis was performed to assess the association of appointment status with MyChart enrollment, after adjusting for other information. The testing level was set at 0.05 . All analyses were done using SAS version 9.4 (SAS Institute Inc., Cary, NC).

\section{Results}

There were 1,113 total visits by 998 individual patients during the 3 selected months. Of these 998 patients, 897 had one visit, 87 had 2 visits, and 14 had 3 visits. In the 998 patients, 673 (67\%) were female, 569 (57\%) were African American, 919 (92\%) spoke English, and the average age was 53.9 years $( \pm 18.9$; range $18-100)$. The distribution of the appointment status was 230 (23\%) no-show, 536 (54\%) showed, and 232 $(21 \%)$ canceled. Fifty-four percent $(\mathrm{n}=540)$ were new visits, $67 \%(\mathrm{n}=670)$ were physician referrals, $50 \%(\mathrm{n}=501)$ had MyChart enrollment, and the visits were equally distributed over the 3 months (35\% October, 31\% February, and 34\% June) (table 1).

\section{Demographic associations}

We found that appointment status is significantly associated with MyChart enrollment and age (table 1). Patients with MyChart enrollment had lower rates of no-show (19\% vs $27 \%$ ) and higher rates of showed (59\% vs $48 \%$ ) compared to patients without MyChart enrollment. Rates of cancellation were similar between the 2 groups ( $22 \%$ vs $25 \%$ ). Younger patients (18-35 and 36-49) had the highest rates of no-show (29\% and $27 \%$, respectively), while older patients (65-79 and 80+) had the lowest rates of no-show (17\% and $18 \%$, respectively). Older patients (65-79 and $80+)$ had the highest rates of canceled appointments $(26 \%$ and $34 \%$, respectively).

In addition, we found significant associations of appointment status with race, language, and method of referral (table 1). This remained true when patients with unknown race, language, and method of referral were excluded (table 1). When considering patients with known race, Caucasian patients had the lowest rate of no-show (14\%) and highest rate of canceled (27\%), African American patients had the highest rate of noshow (25\%) and lowest rate of showed (54\%), and patients of other race-Hispanic, Asian, American Indian, and Native American/Pacific Islander-had the highest rate of showed $(61 \%)$ and lowest rate of canceled (17\%). Patients with unknown race had low rates of showed (28\%) and high rates of no-show (40\%) and canceled (31\%).

Our non-English-speaking patients listed Spanish, Arabic, Chaldean, or Bengali as their preferred language. Despite this small sample size, they had high rates of no-show (34\%) and low rates of canceled (8\%). English-speaking patients had similar rates of no-show (22\%) and canceled (24\%).

Patients with a physician referral had lower rates of no-show ( $20 \%$ vs $28 \%$ ) and canceled visits (19\% vs $28 \%)$ and higher rates of showed (61\% vs $44 \%$ ) compared to self-referral.

The associations of appointment status with appointment type, month of appointment, sex, and the comorbidities 
Table 1 Comparison of appointment status for MyChart enrollment and demographic, comorbidity, and visit information

\begin{tabular}{|c|c|c|c|c|c|c|c|}
\hline Variable & Response & $\begin{array}{l}\text { All patients } \\
(n=998), n(\%)^{a}\end{array}$ & $\begin{array}{l}\text { No-show } \\
(n=230), n(\%)^{b}\end{array}$ & $\begin{array}{l}\text { Showed } \\
(n=536), n(\%)^{b}\end{array}$ & $\begin{array}{l}\text { Canceled } \\
(\mathrm{n}=232), \mathrm{n}(\%)^{\mathrm{b}}\end{array}$ & $\begin{array}{l}\text { Unadjusted } \\
p \text { value }^{c}\end{array}$ & $\begin{array}{l}\text { Adjusted } \\
p \text { value }^{d}\end{array}$ \\
\hline \multirow{2}{*}{$\begin{array}{l}\text { MyChart } \\
\text { enrollment }\end{array}$} & Yes & $501(50)$ & $95(19)$ & $297(59)$ & $109(22)$ & $<0.001$ & 0.011 \\
\hline & No & $497(50)$ & 135 (27) & $239(48)$ & $123(25)$ & & \\
\hline \multirow{2}{*}{$\begin{array}{l}\text { Appointment } \\
\text { type }\end{array}$} & New & $540(54)$ & $111(21)$ & $295(55)$ & $134(25)$ & 0.10 & 0.153 \\
\hline & Return & $458(46)$ & $119(26)$ & $241(53)$ & $98(21)$ & & \\
\hline \multirow{3}{*}{$\begin{array}{l}\text { Month of } \\
\text { appointment }\end{array}$} & October & 348 (35) & $75(22)$ & $198(57)$ & $75(22)$ & 0.199 & 0.874 \\
\hline & February & 308 (31) & $63(20)$ & $168(55)$ & $77(25)$ & & \\
\hline & June & 342 (34) & $92(27)$ & $170(50)$ & $80(23)$ & & \\
\hline \multirow[t]{2}{*}{ Sex } & Male & 325 (33) & $73(22)$ & $171(53)$ & $81(25)$ & 0.683 & 0.847 \\
\hline & Female & $673(67)$ & $157(23)$ & 365 (54) & $151(22)$ & & \\
\hline \multirow[t]{5}{*}{ Age, y } & $18-35$ & $203(20)$ & $59(29)$ & $105(52)$ & $39(19)$ & 0.012 & 0.010 \\
\hline & $36-49$ & $199(20)$ & $54(27)$ & $100(50)$ & $45(23)$ & & \\
\hline & $50-64$ & $297(30)$ & $65(22)$ & $171(58)$ & $61(21)$ & & \\
\hline & $65-79$ & $186(19)$ & $32(17)$ & $105(56)$ & $49(26)$ & & \\
\hline & $80+$ & $113(11)$ & $20(18)$ & $55(49)$ & $38(34)$ & & \\
\hline \multirow[t]{4}{*}{ Race } & Caucasian & $271(27)$ & $37(14)$ & $162(60)$ & $72(27)$ & $<0.001(0.004)^{f}$ & $0.006^{f}$ \\
\hline & $\begin{array}{l}\text { African } \\
\text { American }\end{array}$ & $569(57)$ & $140(25)$ & $310(54)$ & $119(21)$ & & \\
\hline & Other ${ }^{\mathrm{e}}$ & $59(6)$ & $13(22)$ & $36(61)$ & $10(17)$ & & \\
\hline & Unknown & $99(10)$ & $40(40)$ & $28(28)$ & $31(31)$ & & \\
\hline \multirow[t]{3}{*}{ Language } & English & 919 (92) & $202(22)$ & 499 (54) & $218(24)$ & $0.014(0.039)^{g}$ & $0.004^{g}$ \\
\hline & Other & $38(4)$ & $13(34)$ & $22(58)$ & $3(8)$ & & \\
\hline & $\begin{array}{l}\text { Decline/do } \\
\text { not know }\end{array}$ & $41(4)$ & $15(37)$ & $15(37)$ & $11(27)$ & & \\
\hline \multirow[t]{3}{*}{ Referral } & Self & 294 (29) & $82(28)$ & $130(44)$ & $82(28)$ & $<0.001(<0.001)^{f}$ & $<0.001^{f}$ \\
\hline & Physician & $670(67)$ & $137(20)$ & $406(61)$ & $127(19)$ & & \\
\hline & Unknown & $34(3)$ & $11(32)$ & $0(0)$ & $23(68)$ & & \\
\hline \multirow{4}{*}{$\begin{array}{l}\text { Medical } \\
\text { comorbidity }\end{array}$} & Diabetes & $244(24)$ & $49(20)$ & $146(60)$ & $49(20)$ & 0.087 & 0.077 \\
\hline & CAD & $78(8)$ & $23(29)$ & $38(49)$ & $17(22)$ & 0.369 & 0.008 \\
\hline & COPD & $57(6)$ & $10(18)$ & $29(51)$ & $18(32)$ & 0.260 & 0.770 \\
\hline & CKD & $83(8)$ & $14(17)$ & $47(57)$ & $22(27)$ & 0.357 & 0.256 \\
\hline
\end{tabular}

Abbreviations: $C A D=$ coronary artery disease; $C K D=$ chronic kidney disease; $C O P D=$ chronic obstructive pulmonary disease.

a Column percentages.

bow percentages.

${ }^{c} p$ Value from $\chi^{2}$ test.

a $p$ Value from multinomial logistic regression model.

e Other: Hispanic, Asian, American Indian, and Native American/Pacific Islander.

${ }^{f} p$ Value without unknown.

s $p$ Value without decline/do not know. 
diabetes mellitus, coronary artery disease, chronic obstructive pulmonary disease, and chronic kidney disease were not significant (table 1).

In the multivariate analyses, the association between appointment status and MyChart enrollment remained significant after adjusting for the other demographic, comorbidity, and visit information (table 1). The associations of appointment status with age, race, language, referral status, and coronary artery disease were also significant.

We assessed the associations of MyChart enrollment with demographic, comorbidity, and visit information and found that patients with MyChart enrollment were more likely to be female, younger, Caucasian, and referred by a physician (table 2).

\section{Discussion}

Our study investigated and determined an associative relationship between ePP enrollment and no-show rates within an NRC. Characteristics such as geographic location, insurance status, and the duration of time between the date an appointment was made and the date of the actual appointment have been shown to increase the likelihood of noshows. $^{8-12}$ In addition, the demographic of younger age-a small subset of the overall patient population-paradoxically may overwhelmingly contribute to the total no-shows within a clinic. ${ }^{9}$ Prior to EMR implementation, various interventions (i.e., mailed reminders, telephone calls, text messages, automated reminders) to reduce no-shows have been studied. ${ }^{13-16}$

The concept of no-shows takes particular importance when considering the impact upon the resident clinic, where trainees

Table 2 Comparing patients with and without MyChart enrollment

\begin{tabular}{|c|c|c|c|c|}
\hline Variable & Response & $\begin{array}{l}\text { MyChart enrollment } \\
(n=501), n(\%)\end{array}$ & $\begin{array}{l}\text { No MyChart enrollment } \\
(\mathrm{n}=497), \mathrm{n}(\%)\end{array}$ & $p$ Value \\
\hline \multirow[t]{2}{*}{ Appointment type } & New & $256(51)$ & $284(57)$ & 0.055 \\
\hline & Return & 245 (49) & $213(43)$ & \\
\hline \multirow[t]{3}{*}{ Month of appointment } & October & $181(36)$ & $167(34)$ & 0.476 \\
\hline & February & $146(29)$ & $162(33)$ & \\
\hline & June & $174(35)$ & $168(34)$ & \\
\hline \multirow[t]{2}{*}{ Sex } & Male & $127(25)$ & $198(40)$ & $<0.001$ \\
\hline & Female & $374(75)$ & $299(60)$ & \\
\hline \multirow[t]{5}{*}{ Age, y } & $18-35$ & $122(24)$ & $81(16)$ & $<0.001$ \\
\hline & $36-49$ & $113(23)$ & $86(17)$ & \\
\hline & $50-64$ & $140(28)$ & $157(32)$ & \\
\hline & $65-79$ & $85(17)$ & $101(20)$ & \\
\hline & $80+$ & $41(8)$ & $72(14)$ & \\
\hline \multirow[t]{3}{*}{ Race } & Caucasian & $165(35)$ & $106(25)$ & 0.008 \\
\hline & African American & $282(59)$ & $287(68)$ & \\
\hline & Other & $30(6)$ & $29(7)$ & \\
\hline \multirow[t]{2}{*}{ Language } & English & $474(97)$ & $445(95)$ & 0.144 \\
\hline & Other & $15(3)$ & $23(5)$ & \\
\hline \multirow[t]{2}{*}{ Referral } & Self & $131(27)$ & $163(34)$ & 0.018 \\
\hline & Physician & $354(73)$ & $316(66)$ & \\
\hline \multirow[t]{4}{*}{ Medical comorbidity } & Diabetes & $113(23)$ & $131(26)$ & 0.162 \\
\hline & CAD & $34(7)$ & $44(9)$ & 0.224 \\
\hline & COPD & $24(5)$ & $33(7)$ & 0.208 \\
\hline & CKD & $34(7)$ & $49(10)$ & 0.079 \\
\hline
\end{tabular}

Abbreviations: $C A D=$ coronary artery disease; $C K D=$ chronic kidney disease; $C O P D=$ chronic obstructive pulmonary disease. 
have a relatively reduced number of patient encounters compared to attending physicians. As Sir William Osler said, "He who studies medicine without books sails an uncharted sea, but he who studies medicine without patients does not go to sea at all." ${ }^{17}$ From our findings, residents miss out on seeing almost one quarter of patient volume (approximate 23\% no-show rate), or approximately 4 missed patient encounters per resident per month. Furthermore, we observed that enrollment in the ePP correlated with lower no-show rates, which has been demonstrated by several other groups. ${ }^{6,13}$ It may seem intuitive that a younger generation would tend to be higher portal adopters; however, we determined that patients who were female, Caucasian, and referred by a physician also adopted portals at a higher rate. These demographic findings are consistent with those previously seen in a variety of practice settings; however, in addition, preferred language, type of insurance, and economic status contributed to portal adoption. ${ }^{5,7,13,18}$ Given there is no singular factor contributing to portal adoption, there have been several modalities and suggestions to encourage utilization of this resource. ${ }^{19,20}$ It remains uncertain how this translates into an NRC; thus further investigation and validation will be necessary.

\section{Limitations}

Our study has several limitations, mainly those inherent to retrospective investigations such as being prone to certain biases and unforeseen confounders. In addition, we sampled only 3 months to capture different time points within the academic year and seasons, and we were only able to determine if a patient enrolled in MyChart but not the rate of ePP utilization. Also, we did not capture the gap between the date when the appointment was scheduled and the date of the actual appointment. Relying solely on the ePP may be feasible for certain populations; however, it likely should serve as a supplement to additional modalities. Furthermore, how noshows are defined by different institutions may influence the generalizability of our data. Overall, no-shows are of great detriment to the education of trainees and to the stability of our fragile health care system. Further investigation is necessary to determine the most effective approach to decreasing no-shows and increasing patient adherence to clinic appointments, which will ultimately benefit patient wellbeing, resident education, and provider satisfaction.

\section{Author contributions}

K. Shah: study design, study concept, data collection, drafting and revising the manuscript. A. Alshammaa: study design, data collection. M. Affan: data collection. L. Schultz: data analysis. T. Walbert: study design, manuscript revision. I. Zaman: study concept, manuscript revision. All authors reviewed the final submitted manuscript.

\section{Acknowledgment}

Susan MacPhee (Henry Ford Hospital, Department of Neurosurgery) and Stephanie Stebens (Henry Ford Hospital, Sladen Library) edited the manuscript for non-intellectual content.

\section{Study funding}

No targeted funding reported.

\section{Disclosure}

K. Shah, A. Alshammaa, M. Affan, and L. Schultz report no disclosures relevant to the manuscript. T. Walbert is an advisory board member for AbbVie and Tocagen and receives travel support from Novocure and Tocagen. I. Zaman reports no disclosures relevant to the manuscript. Go to Neurology. org/ $\mathrm{N}$ for full disclosures.

\section{References}

1. Wright A, Feblowitz J, Samal L, McCoy AB, Sittig DF. The Medicare electronic health record incentive program: provider performance on core and menu measures. Health Serv Res 2014;49:325-346.

2. Hsiao CJ, Hing E, Socey TC, Cai B. Electronic health record systems and intent to apply for meaningful use incentives among office-based physician practices: United States, 2001-2011. NCHS Data Brief 2011:1-8.

3. Jamoom E, Yang N. National electronic health records survey: 2015 State and National electronic health record adoption summary tables. Available at: cdc.gov/nchs/ data/ahcd/nehrs/2015_nehrs_web_table.pdf. Accessed January 11, 2018.

4. Jhamb M, Cavanaugh KL, Bian A, et al. Disparities in electronic health record patient portal use in nephrology clinics. Clin J Am Soc Nephrol 2015;10:2013-2022.

5. Goldzweig CL, Orshansky G, Paige NM, et al. Electronic patient portals: evidence on health outcomes, satisfaction, efficiency, and attitudes: a systematic review. Ann Intern Med 2013;159:677-687

6. Kipping S, Stuckey MI, Hernandez A, Nguyen T, Riahi S. A web-based patient portal for mental health care: benefits evaluation. J Med Internet Res 2016;18:e294.

7. Girault A, Ferrua M, Lalloué B, et al. Internet-based technologies to improve cancer care coordination: current use and attitudes among cancer patients. Eur J Cancer 2015;51:551-557.

8. Neal RD, Lawlor DA, Allgar V, et al. Missed appointments in general practice: retrospective data analysis from four practices. Br J Gen Pract 2001;51:830-832.

9. Majeroni BA, Cowan T, Osborne J, Graham RP. Missed appointments and Medicaid managed care. Arch Fam Med 1996;5:507-511.

10. Whittle J, Schectman G, Lu N, Baar B, Mayo-Smith MF. Relationship of scheduling interval to missed and cancelled clinic appointments. J Ambul Care Manage 2008;31:290-302.

11. Bean AG, Talaga J. Predicting appointment breaking. J Health Care Mark 1995; 15: 29-34.

12. Izard T. Managing the habitual no-show patient. Fam Pract Manag 2005;12:65-66.

13. Horvath M, Levy J, L'Engle P, Carlson B, Ahmad A, Ferranti J. Impact of health portal enrollment with email reminders on adherence to clinic appointments: a pilot study. J Med Internet Res 2011;13:e41.

14. Fairhurst K, Sheikh A. Texting appointment reminders to repeated non-attenders in primary care: randomised controlled study. Qual Saf Health Care 2008;17:373-376.

15. Parikh A, Gupta K, Wilson AC, Fields K, Cosgrove NM, Kostis JB. The effectiveness of outpatient appointment reminder systems in reducing no-show rates. Am J Med 2010;123:542-548.

16. Macharia WM, Leon G, Rowe BH, Stephenson BJ, Haynes RB. An overview of interventions to improve compliance with appointment keeping for medical services. JAMA 1992;267:1813-1817.

17. Johns Hopkins Medicine. The four founding physicians [online]. Available at: hopkinsmedicine.org/about/history/history5.html. Accessed January 6, 2018.

18. Wallace LS, Angier H, Huguet N, et al. Patterns of electronic portal use among vulnerable patients in a nationwide practice-based research network: from the OCHIN practice-based research network (PBRN). J Am Board Fam Med 2016;29: 592-603.

19. Baldwin JL, Singh H, Sittig DF, Giardina TD. Patient portals and health apps: pitfalls, promises, and what one might learn from the other. Healthcare 2017;5:81-85.

20. Health IT Playbook. Available at: healthit.gov/playbook/pe/introduction/. Accessed July 3, 2018. 


\section{Neurology}

\section{Education Research: Electronic patient portal enrollment and no-show rates within a neurology resident clinic}

Kavit Shah, Abdullah Alshammaa, Muhammad Affan, et al. Neurology 2019;92;50-54

DOI 10.1212/WNL.0000000000006685

\section{This information is current as of December 24, 2018}

Updated Information \& Services

References

Subspecialty Collections

Permissions \& Licensing

Reprints including high resolution figures, can be found at: http://n.neurology.org/content/92/1/50.full

This article cites 16 articles, 4 of which you can access for free at: http://n.neurology.org/content/92/1/50.full\#ref-list-1

This article, along with others on similar topics, appears in the following collection(s):

All Education

http://n.neurology.org/cgi/collection/all_education All Practice Management

http://n.neurology.org/cgi/collection/all_practice_management Computer use in education

http://n.neurology.org/cgi/collection/computer_use_in_education Electronic medical records

http://n.neurology.org/cgi/collection/electronic_medical_records

Information about reproducing this article in parts (figures,tables) or in its entirety can be found online at:

http://www.neurology.org/about/about_the_journal\#permissions

Information about ordering reprints can be found online:

http://n.neurology.org/subscribers/advertise

Neurology ${ }^{\circledR}$ is the official journal of the American Academy of Neurology. Published continuously since 1951, it is now a weekly with 48 issues per year. Copyright (O 2018 American Academy of Neurology. All rights reserved. Print ISSN: 0028-3878. Online ISSN: 1526-632X.

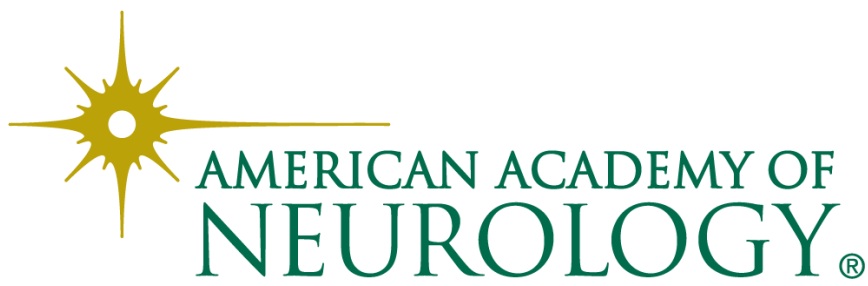

